\title{
Sulama Şebekelerindeki Sanat Yapılarının Yeterliliğinin Belirlenmesi *
}

\author{
Halit APAYDIN ${ }^{1} \quad$ Fazlı ÖZTÜRK \\ Geliş Tarihi : 06.05.1997
}

\begin{abstract}
Özet : Bu çalışmada, Köy Hizmetleri Genel Müdürluğu, Konya II Müdürlüğú sorumluluk alanı içinden seçilen 7 sulama şebekesindeki sanat yapılarınin yeterliliğinin belirlenmesi amaçlanmiştır.

Sulama şebekelerinde suyu iletmek, dağıtmak, kontrol etmek ve ölçmek amacıyla kullanilan geçiş yapisı, sifon, şüt, dúşü, akeduk, çökeltim havuzu, savak, priz, çek, sel geçidi, otomatik sifon ve tahliye yapılarının (a) yer seçimi, (b) yapısal özellikler, (c) hidrolik esaslar ve (d) işletme açısından optimum faydayı sağlayabilmesi için taşıması gereken özellikler saptanımış, mevcut sistemlerin bu ozzellikleri taşıyıp taşımadığı araştırılmış ve sonuçlarla beraber örıeriler ortaya konmuştur.
\end{abstract}

Anahtar kelimeler: Sulamada sanat yapıları, sulama yapılarının özellikleri.

\section{Determining of Adequacy of Farm Irrigation Structures in the Irrigation Schemes}

\begin{abstract}
The aim of this study is determining of adequacy of farm irrigation structures in General Directorate of Rural Service's seven irrigation schemes which in Konya district.

Conveyance, distribution, control and measurement structures are transition structures, siphon, chute, drop, aqueduct, stilling basin, flume, weir, turnout, check, culvert, automatic siphon and spillway in an irrigation scheme. These irrigation structures investigate to determine placement, structural specialty, hydraulic and operation characteristic and than some proposing was motioned.
\end{abstract}

Key words: Farm irrigation structures, characteristics of farm irrigation structures.

\section{Giriş}

Su, bitki ve toprak, tarımın birbirinden ayrı düşünülemez üç parçasıdır. En az masrafla en fazla ürün alabilmek için her bir parça en uygun koşulla tarımda yerini almalıdır. Toprak, tarlanın sürülmesi, tesviye edilmesi gibi tarla için faaliyetlerle tarıma hazırlanırken yetiştirilecek bitki olarak iklime en uygun bitki ve tür saptanmalıdır. Üçüncü unsur olan su ise bitkiye intiyaç duyduğunda, ihtiyacı kadar verilmelidir. Bunu sağlamak için sulama sisteminin proje, yapım ve işletmesine gereken önem verilmelidir.

Türkiye'de su kaynaklarının geliştirilmesine ilişkin sorunlar, iki alt başlıkta toplanabilir. Doğal kaynakların yeterince kullanilmamasından ileri gelen daha çok ekonomik kökenli olan ve ikinci grup olarak uygulama sırasında (planlama ve yapım dahil) ortaya çıkan, bazen beklenen ancak çoğu kez beklenmeyen nitelikteki sorunlardır. Ikinci grup sorunlar, önceliklerin iyi seçilememesi, yanlış planlama, yapım sırasında meydana gelen hatalar, kötü işletim tekniklerinin kullanılması, tutarsız politik-ekonomik ve sosyal yaklaşımlar sonucu oluşmaktadır (Şahin ve Güreli 1986, Özşahin 1991)

Sanat yapılarının sulama sistemlerinde önemli bir fonksiyona sahip oldukları bilinmektedir. Hazırlanan çeşitli sulama projeleri uygulama aşamasını tamamladıktan sonra çeşitli nedenlerle işletmeye açılamamakta veya projede tasarlanan şekilde fonksiyonel olamamaktadır. Ayrıca işletmeye açılan sulama projelerinde sanat yapıları açısından da bazı eksiklikler ortaya çıkabilmektedir. Bu çalışmada; sulama şebekelerindeki sanat yapılarının yer seçimi, yapısal özellikleri, hidrolik esasları ve işletme açısından eksikliklerinin belirtilmesi, eksikliklerinin giderilmesi için önerilerin ortaya konması planlanmıştır.

\section{Materyal ve Yöntem}

Bu bölümde araştırma alanı ile ilgili genel bilgiler verilmiş ve kullanılan metotlar açıklanmıştır.

\section{Materyal}

Çalıșmada Konya ili sınırları içinde yer alan ve Köy Hizmetleri Genel Müdürlüğü (KHGM) tarafından yaptırılan 7 sulama işletmesi ele alınmıştır. Bu işletmeler, KonyaBeyşehir-Göçü, İsaköy sulama tesisi, Konya-SeydişehirBostandere sulama tesisi, Konya-Doğanhisar-Yenice sulama tesisi, Kanya-Seydişehir-Gökçehüyük sulama tesisi, Konya-Beyşehir-Göçeri sulama tesisi, KonyaAkşehir-Ulupınar sulama tesisi, Konya-Doğanhisar-Çetme sulama tesisidir.

\section{Yöntem}

Bu bölümde sulama şebekelerinde suyu iletmek, dağıtmak, kontrol etmek gibi amaçlarla kullanılan sanat yapıları yer seçimi, yapısal özellik, hidrolik esaslar ve işletme açısından sahip olmaları gereken özellikler belirtilmiştir.

\footnotetext{
Yüksek Lisans Tez i Özeti.

'Araş. Gör., Ankara Üniv.Ziraat Fak. Tarımsal Yapılar ve Sulama Bölümü, Ankara.

${ }^{2}$ Doç. Dr., Ankara Üniv. Ziraat Fak. Tarımsal Yapılar ve Sulama Bölumü. Ankara.
} 


\section{a. Iletim yapıları}

Açık kanal sistemindeki su iletim yapıları, dağıtılan suyun erozyona sebep olmadan düzenli ve güvenilir bir şekilde parsellere ulaştırılmasını sağlamak amacıyla kullanılır (Kraatz and Mahajan 1975).

Sulama projelerinde yapilan hidrolik hesaplar; a) alternatif tasarımlar arasında en ekonomik, uygun ve randımanlı olanı seçmek, b) suyun, sulanacak alana olabilecek en yūksek miktarda, güvenli ve randımanlı olarak iletmek, c) gerek bölgesel ve gerekse tüm proje alanında teknolojik gelişme sağlayarak sonraki işletim ve bakım maliyetlerini olabildiğince azaltmak için gereklidir (Kraatz and Mahajan 1975, Aküzüm ve Öztürk 1988).

\section{Geçiş yapısı}

Sulama kanallarında kesit değişince, değişik iki kanal kesitini birbirine bağlayan geçiş yapıları yapılarak oluşabilecek enerji kayıpları azaltılır. Geçiş yapıları genellikle, trapez, dikdörtgen ve daire kesiti bir diğerine bağlar (Aküzüm ve Öztürk 1988).

\section{Sifon}

Sulama kanallarının çok fazla sürüntü malzemesi getiren akarsuları, derin vadileri ve köprü yapımına uygun olmayan yol veya demiryollarını kesmesi halinde genellikle ters sifon olarak tanımlanan sifonla geçiş sağlanır (Şekil 1) (Aküzüm ve Öztürk 1988, Anonim 1992).

\section{Düşü}

Düşüler, suyu yüksek kotlardan, daha düşük bir kota enerjisini kırarak, emniyetli olarak indiren yapılardır (Şekil 2). Düşülerin, dik, eğik, basamaklı ve borulu olmak üzere değişik şekilleri vardır (Bilen 1988, Anonim 1992).

\section{Şüt}

Şütler, mansap su seviyesini ve akım hızını düşürmek için kanallara inşa edilen kontrol yapılarıdır. Seviye farkları 4.5 metreden büyük olan kanallar arasına yerleştirilirler (Kraatz and Mahajan 1975).

\section{Akedüik}

Sulama kanallarını geniş ve debisi büyŭk derelerden geçirirken dere derinliği 5 m'yi geçmiyor ise akedük de uygulanabilir (Şekil 3) (Aküzüm ve Öztürk 1988).

\section{Çökeltim havuzu}

Çökeltim havuzları kanallardaki sedimentin çökeltilmesi amacıyla kullanılır. Su jeti havuza düşerek, buradaki suya çarpmakta ve enerjisi kırılmaktadır. Enerjinin kaybolmasıyla hız dūşmekte, sediment çökelmekte ve su mansaba doğru daha düşük hızla akmaktadır (Bosch et al 1993).

\section{b. Kontrol yapılar}

Kontrol yapıları sulama kanallarındaki su seviyesini kontrol ederek istenilen seviyede tutmaya ve su miktarını ölçmeye yarar. Ayrıca kanalın taşıyabileceğinden fazla su gelmesi halinde fazla suyu araziye zarar vermeden uzaklaştırır (Aküzüm ve Öztürk 1988



Sekil 1. Sifon (Bosch et al 1993).
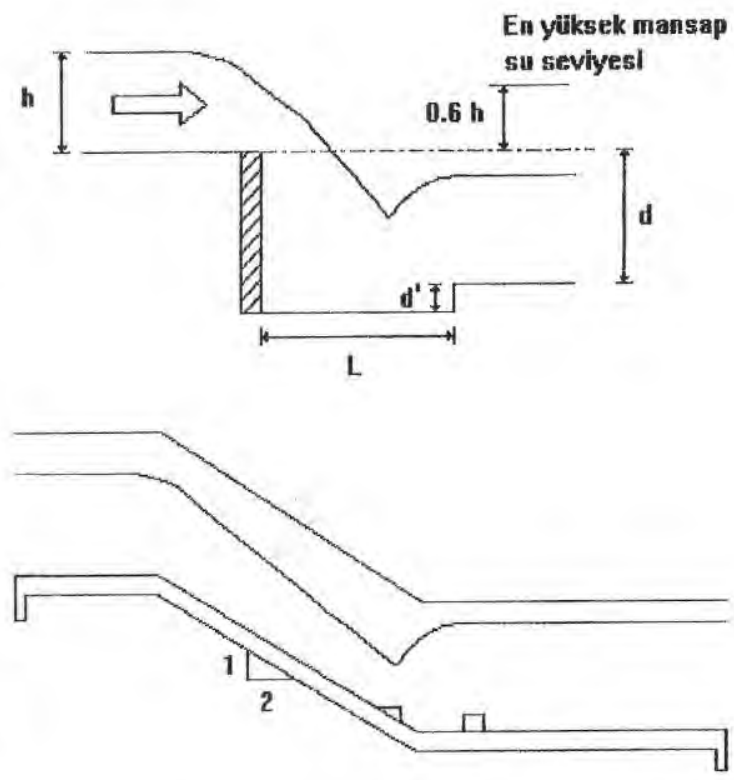

Şekil 2. Dik ve eğik duşa (Bilen 1988, Aküzüm ve Óztürk 1988 , Kraatz and Mahajan 1975, Anonim 1982).

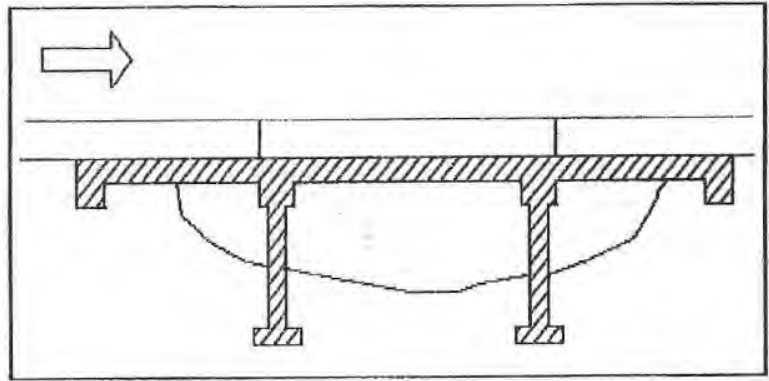

Şekil 3. Akedük (Bilen 1988, Aküzum ve Öztürk 1988). 


\section{Debi ölçme yapıları}

Sulama şebekelerinde suyun yeterli ve düzenli bir şekilde dağıtılması, aşırı su kullanımından kaynaklanan tuzluluk, alkalilik, tabansuyu ve erozyon gibi sorunların önlenmesi ancak planlı ve ölçülü su dağıtımı ile gerçekleșebilit (Şahin ve Güreli 1986).

Sulama suyu ölçümleri için kullanılan standart keskin kenarlı savak tipleri; a) dikdörtgen savaklar, b) dik açılı üçgen savaklar, c) yamuk (Cipoletti) savaklardır. Bu savaklar, isimlerini geometrik şekillerinden almışlardır (Şekil 4).

Kanal kesitine uygunluklarindan dolayı dikdörtgen ve Cipolletti savaklari kullanılmakla beraber, üçgen savakların kullanılmasınin mümkün olduğu yerlerde Cipolletti ve dikdörtgen savakların kullanılması tavsiye edilmez (Özsoy 1968, Özbek 1989).

Savağın membasında biriken sediment savağa yaklaşım geometrisini değiştirir ve debi miktarı genellikle teorik formüllerle hesaplanan değerin üzerinde çıkar. Şekil 5 'de ki $P, W$ ve $X$ değerlerine göre sedimentasyondan kaynaklanan debi değişimleri Çizelge 1 'de verilmiştir (Israelsen and Hansen 1967).

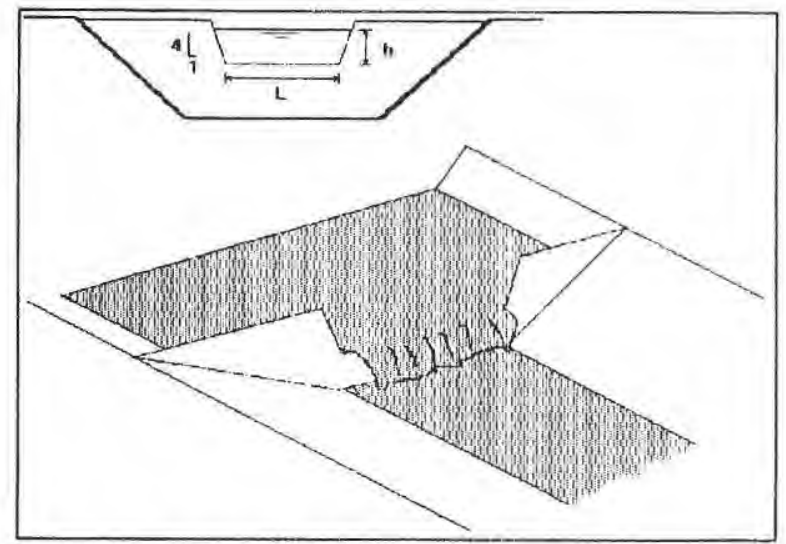

Şekil 4. Cipoletti savağı (Israelsen and Hansen 1967, Özsoy 1968, Bos 1989, Anonim 1992).

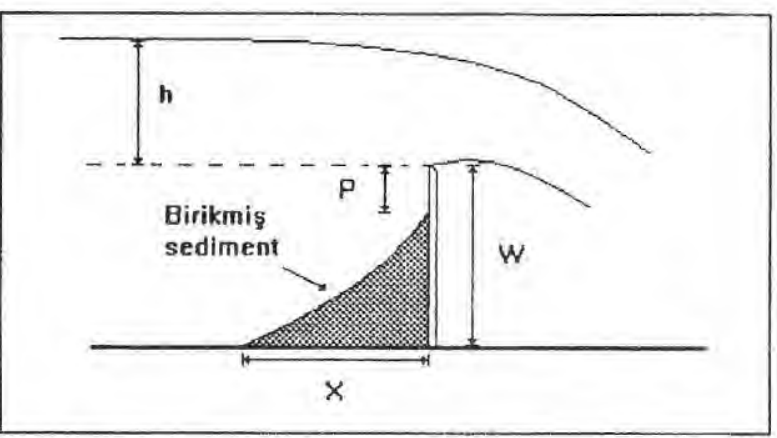

Şekil 5. Savağın memba tarafında sediment birikimi (Israeisen and Hansen 1967).
Çizelge 1. Debi ölçümünde sedimentasyondan kaynaklanan hatalar (\%) (Israelsen and Hansen 1967).

\begin{tabular}{|c|c|c|c|c|c|c|}
\hline \multirow{2}{*}{$P M$} & \multicolumn{7}{|c|}{$\times / W$} \\
\cline { 2 - 7 } & 0 & 0.5 & 1.0 & 1.5 & 2.0 & 2.5 \\
\hline 0 & 0 & 10 & 13 & 15 & 16 & 16 \\
\hline 0.25 & 0 & 5 & 8 & 10 & 10 & 10 \\
\hline 0.50 & 0 & 3 & 4 & 5 & 6 & 6 \\
\hline 0.75 & 0 & 1 & 2 & 2 & 3 & 3 \\
\hline 1.00 & 0 & 0 & 0 & 0 & 0 & 0 \\
\hline
\end{tabular}

\section{Yatay eksende daraltmalı savaklar:}

Bu savakların şekil ve biçimleri, akış kesitini yatay bir düzlemde büzerek akış hızın arttıracak şekilde yapılmıştır. Belli bir debiyi geçirmek için, düşey eksende daraltmalı savaklara göre daha az enerji yüküne intiyaç gösterirler (Anonim 1992).

\section{Parshall savağı:}

Amerikan kökenli olup, Colorado State Universitesinde R. L. Parshall tarafından geliştirilmiştir (Şekil 6). Bu savaklar ölçüm için büyük bir düşüye intiyaç göstermediklerinden hafif eğimli kanallarda elverişli bir şekilde kullanılabilir Yapımları zordur (Anonim 1992)

Parshall savaklarının büyüklükleri, boğaz genișliği (W) ile belirtilir. Bu ölçü aynı zamanda ölçülebilen debi miktarlarını da sınırlar.

\section{Kesik boğazlı savak:}

Ilk olarak Hindistan'da geliştirilmiş olup, $1967^{\prime}$ den sonra Colorado State Üniversitesinden Skogerboe ve arkadaşları tarafından yaygınlaştırılmıştır (Şekil 7).

\section{Orifis:}

Orifisler, genel olarak kanal kesitine dik olarak yerleştirilen ve su seviyesinin altında suyun akışını sağlayan dikdörtgen veya dairesel bir açıklığı bulunan levhalardır. Akım durumuna göre serbest veya batık şekilde çalışır (Şahin ve Güreli 1986).

\section{Su alma yapıları}

Kanallardan istenilen miktar ve kotta su almayı sağlayan yapılara priz denir. Su alma da basit prizler yanında sabit yüklü orifisde kullanılabilir (Şekil 8). Şekil 9 da kanal üzerinde priz yerleşimine uygun yerler belirlenmiştir (Şahin ve Güreli 1986, Bilen 1988, Anonim 1992).

\section{Su seviyesi kontrol yapıları}

Sulama kanallarındaki su seviyesi maksimum debi ve dolayısı ile maksimum seviyenin oluşmadığı bir anda ana kanaldan ayrilan herhangi bir kanal üzerinde çiftçilerin hepsinin birden su istemeleri mümkündür. Bu durumda maksimum su seviyesine göre projelendirilmiş prizlerden istenilen kotta ve debide su almak mümkün olmayacağından kanaldaki su seviyesini kabartarak 

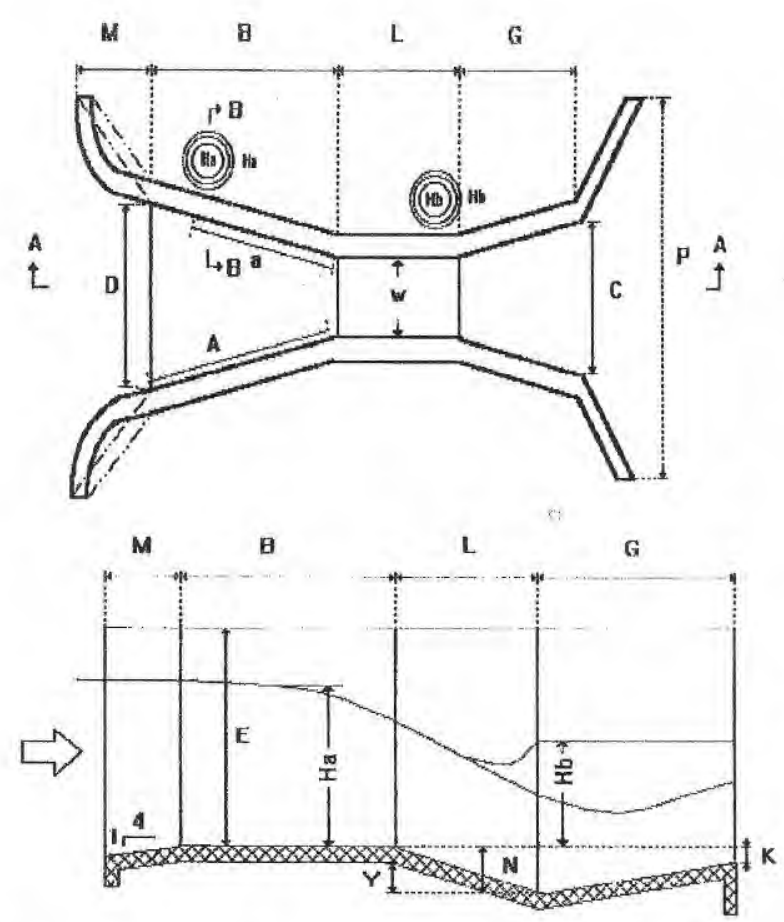

Şekil 6. Parshall savağı (Israelsen and Hansen 1967, Anonim 1973 Özsoy 1968, Kraatz and Mahajan 1975, Bos 1989, Anonim 1992).

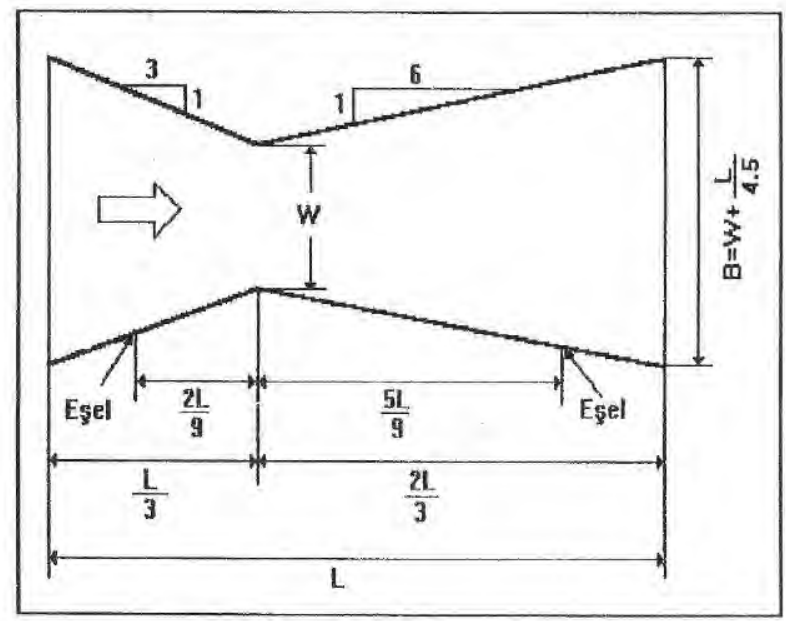

Şekil 7. Kesik boğazil savak (Israelsen and Hansen 1967, Özsoy 1968, Kraatz and Mahajan 1975, Bos 1989, Anonim 1992).

istenilen duruma getirmek amacıyla çek yapıları kullanılır. Çek, aynı zamanda kanalın çeşitli bölümlerindeki geçici dalgalanmaları önlemeye, kanal eğimini düşürmeye, suyun enerjisini kırmaya ve hız kontrolüne yardımcı olur (Bilen 1988, Anonim 1992, Kraatz and Mahajan 1975).

\section{Emniyet yapılanı}

Bu yapılar sulama ve drenaj kanallarınin emniyetini sağlarlar. Sulama kanallarında yamaç sularının kanala alınması veya ani priz kapatmalarında kanallardaki su seviyesini kontrol eden otomatik sifon, yamaç sularının kanala zarar vermemesi için yapılan yamaç suyu alma tesisleri, yan derelerin taşkın sırasında kanala zarar vermeden geçebilecekleri sel geçitleri bu yapilardandir (Aküzüm ve Öztürk 1988).

\section{Sel geçitleri:}

Sel geçitleri 2 gruba ayrilırlar. Yan derenin talveg kotuna göre taşkın suyu, ya kanalın üstünden ya da altından geçirilir. Sel suları kanalın üstünden geçiriliyorsa ast sel geçidi, kanalın altından geçiriliyorsa alt sel geçidi denir (Şekil 10) (Aküzüm ve Öztürk 1988).

\section{Yamaç suyu alma tesisleri:}

Ana kanal güzergahı üzerindeki yamaçtan su geliyorsa ve suyun debisi ve taşıdığı sediment miktarı az, kalitesi sulama suyuna zarar vermeyecek durumda ise bu suyu sulama kanalına alınması amacıyla yamaç suyu alma tesisi inşa edilebilir. Yan dere debisi ve taşıdığı sediment miktarı fazla ise sel suları alt veya üst sel geçidi ile kanala zarar vermeden uzaklaştırır.

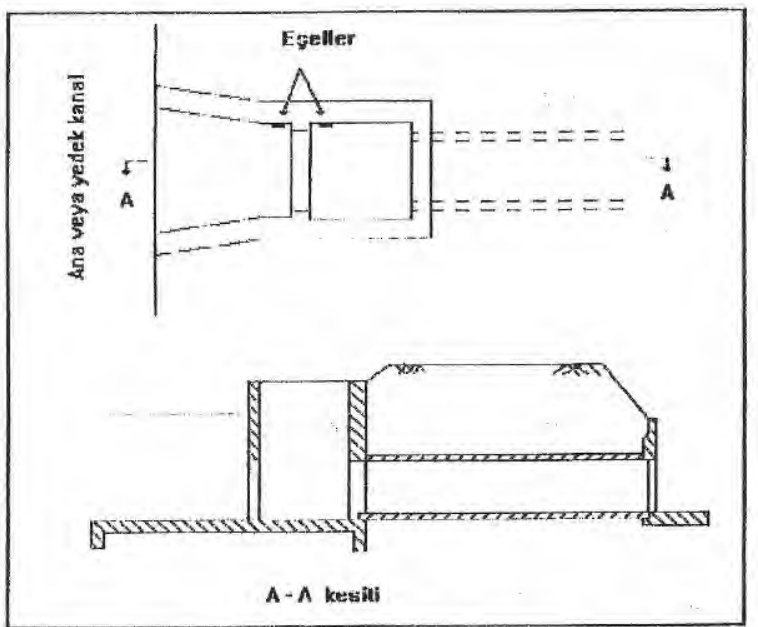

Şekil 8. Sabit yâklu orifis (Bilen 1988, Anonim 1982, Aküzäm ve Öztưrk 1988, Kraatz and Mahajan 1975).

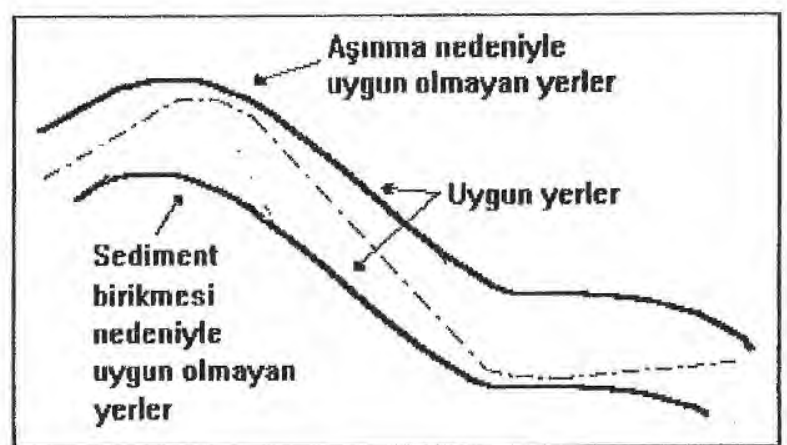

Sekil 9. Priz yerleşimine uygun yerler (Bosch et al 1993, Ueda 1990). 




Şekil 10. Alt sel geçidi (Bilen 1988, Akuzum ve Özturk 1988, Anonim 1992).

\section{Su dağıtım yapıları}

Ana kanaldan daha küçük kanallara su alınması çok çeşitli yollarla olabilir. $\mathrm{Yap}_{\text {i }}$ ana kanaldaki suyun \% 25 'inden daha fazlasını alıyorsa su dağıtım yapısı, daha azını alıyorsa su alma yapısı olarak tanımlanabilir. Su dağıtım yapıları hareketli ayırıcılarla donatılabilir. Bu ayırıcılar akımdaki değişiklikler ve ihtiyaç miktarındaki değişime göre akım miktarını ayarlayabilir (Kraatz and Mahajan 1975).

\section{c. Geçit yapıları}

Sulama kanalları uzun mesafeler katettiğ için, bazen yerleşim yerleri arasındaki kara ve demiryolunu kesebilir. Bu tür geçişler genellikle köprü veya menfez biçiminde olur. Kararlı zeminlerde köprü, kararlı olmayan zeminlerde menfez yapılması uygundur.

\section{d. Sanat yapılarının şebeke maliyeti içindeki oranlarının belirlenmesi}

Sanat yapılarının şebeke maliyeti içindeki oranlarının belirlenmesi amacıyla; sanat yapısının yapımını oluşturan iş ve malzemelerin miktarları, o yıla ait birim fiyatlarıyla çarpılarak tek bir yapının maliyeti tespit edilmiş ve maliyetin toplamı alınarak bulunan toplam sanat yapısı maliyeti şebekenin II. keşif bedeline oranlanarak yapının şebeke maliyeti içindeki yüzdesi bulunmuştur.

\section{Bulgular ve Tartışma}

Konya ilindeki 7 sulama şebekesi ayrı ayrı ele alınarak her şebekedeki iletim, dağıtım, kontrol ve geçit yapıları yer seçimi, yapısal özellikler, hidrolik esaslar ve işletme açısından incelenmiş olup sonuçlar aşağıda verilmiştir.

İncelenen sulama şebekelerinin hiçbirinde su ölçüm yapısı bulunmamaktadır. Sulama randımanını tespit etmek ve arttırmak, bilinçli ve planlı bir sulama yapmak bu bakımdan mümkün olmamaktadır. Plansız ve bilinçsiz sulama yapilmaktadır.
Sulama şebekesinde, sifonlar içindeki suyu boşaltmak amacıyla kullanılan boşaltım vanaları dışında herhangi bir emniyet yapısı bulunmamaktadır. Bu ise beklenmedik durumlar karşısında şebekenin ve şebekenin hizmet ettiği alanların zarar görmesine sebep olabilir.

Sel sularını doğal akarsu yatağına vermek için yapılan sel geçitleri tüm sistemde standart boyutta inşa edilmiştir.

Benzer şekilde su alma yapısı maliyeti, gerekli olan su yükü, sudaki sediment miktarına bakılmaksızın tek tip olarak projelendirilmiştir.

Proje dosyalarında sanat yapılarının hidrolik hesaplamalarına yeterince yer ayrılmamaktadır. Kesin hesap dosyasında yer alan bir yapı yeşil defterde ya hiç bulunmamakta yada detayları bulunmamaktadır. Yol geçidi, priz, sel geçidi, akedük gibi yapılar tipleştirildiği için hidrolik açıdan beklenmedik durumlar ortaya çıkmasa da ekonomik olmamaktadır.

Yöre halkından oluşan çiftçi gruplarına devredilen sulama şebekeleri içinde iyi bir organizasyon ve çiftçiler için eğitim çalışması olmadığı için çeşitli işletme sorunları ortada kalmaktadır.

Pek çok şebeke de kanallara alınan su miktarı genelde çiftçinin talebini karşılamasa da bazı zamanlarda sisteme alınan su ana kanal sonunda sistemi terketmekte ve boşa gitmektedir.

Şebekelerde inşa edilmiş sifonlar uygun yerlere yapılışstır. Aynı yerde akedük tesisinin emniyetsiz ve daha pahalı olacağı görülmüştür.

Su dağıtım yapısı olarak genelde köşe havuzları yapılmıştır. Basit sistemler için bu yapılar yeterlidir.

Ele alınan projelerde mevcut olan geçiş yapısı ve akedüklerin görevlerini tam olarak yerine getirdikleri görülmüştür.

Arazide yapılan incelemeler sırasında görülen şüt, düşü, çek gibi yapılar projelerde bulunmamaktadir. Herhangi bir hidrolik hesabı yapılmamış bu yapılar inşaat sırasında topoğrafyaya göre inşa edilmekte, istenileni bazen sağlamamakta, bazen sağlamaktadır. Şüt sonunda enerji kırıcı havuz bulunmamaktadır. 
Sulama şebekeleri projelendirilirken çiftçi ile iletişim kuruimamakta, sosyal durum, arazi mülkiyet dağılımı göz önüne alınmamaktadır. Bazı projelerde $2-3$ parsele bir çiftlik prizi ayrımış, bu durum ise suyu alan ilk parselle diğer parsel sahipleri arasında anlaşmazlıklara yol açmıștır. Diğer parsel sahipleri münferit olarak suyu alabilmek için kanalın tabanını kırıp priz olarak kullanmaktadırlar. Benzer şekilde sistemin inşasından sonra bazı yerlerde çiftçiler tarafından yol geçidi yapilmaktadir.

Bazı sulamalarda kanalların içinde oldukça fazla sediment biriktiği tespit edilmiştir. Kanalda sediment birikimi, bakım çalışmalarının eksikliği yanında su alma yapısının sediment girişini engelleyecek şekilde projelendirilmediğini, çökeltim havuzlarına yeterince önem verilmediğini göstermektedir.

KHGM tarafindan yapılan sulama projelerinde amaç sulama ile yörenin gelirini artırmaktır. Ancak bu amaca hizmet ederken gerçekçi, en yüksek faydayı en az maliyetle sağlayacak projeler hazırlanmalı, siyasi baskılara boyun eğilmemelidir. Projeden sorumlu ziraat mühendisinin çiftçi ile iyi bir iletişim kurmalı, her aşamada projeden yararlananlara yardımcı olmalıdır. Incelemelerimiz sırasında bu işe uzun yıllarını vermiş mühendislerin yeterince tecrübe kazandıkları gözlemlenmiştir.

Incelenen 7 sulama şebekesinden sadece üçūnün ilk proje esas alınarak inşa edildiği saptanmıştır. Pek çok tesisin inşaası sırasında ilk projesine göre büyük değişiklikler yapılmıştır. Bunun sebebi projeleme sırasında yeterli arazi çalışması yapılmaması, yeterli özenin gösterilmemesi yada ödenek eksikliği olabilir. Planlama ile inşa arasında bâyâk farklılıklar olduğunda; - Projede ilk olarak hedeflenen çiftçilere erişilememekte, - Proje amaçlanandan daha az alana hizmet etmekte. - Maliyet çok artmaktadır.

Suyun iletildiği yörelerdeki çiftçilerin kültür, eğitim seviyesi ve mali durumu da sistemin aptimum kullanılması ve yaşatılması için önemli bir faktördür. Suyun kendisine sağlayacağı faydaları bilen, ileri görüşı̈ çiftçilerin olduğu yörelerde sistern çok daha randımanlı ve uzun zaman hizmet ederken; aksi durumlarda suyun sağlayacağı fayda daha az olmaktadır.

Incelemeler sırasında projede belirtilen bitki desenine çiftçinin uyması durumunda kanal kapasitesinin ihtiyacı karşılayabileceği saptanmıştır. Ancak çiftçilerin projede belirlenen bitki desenine genellikle uymadikları tespit edilmiştir. Çiftçilerimizin projede belirtilen bitki desenine uymaları için herhangi bir yaptırım bulunmamaktadir.

\section{Sanat yapılarının şebeke maliyeti lçindeki oranlar}

Sulama şebekelerindeki sanat yapılarinın maliyetinin şebeke maliyetine oranının belirtilmesi amacıyla düzenlenen Cizelge 2'de de görülebileceği gibi genel olarak bir sulama şebekesinde sanat yapiları, şebeke maliyetinin \% 5.30 - \% 22.56'sını oluşturmaktadır.
Maliyet oranları arazinin topoğrafyasına, su kaynağına, su dağıtım yóntemine, arazi mọlkiyet durumuna, kullanılan suyun äcretlendirme yöntemine bağı olmaktadir.

\section{Öneriler}

Araștırma ve incelemeler sirasında tespit edilen eksiklik ve aksaklıkłarın giderilmesi amacıyla öneriler aşağıda belirtilmiştir.

a) Çok parçalı arazilerin bulunduğu yerlerde sulama projesi hazırlanırken toplulaştırma çalışması da birlikte yapılmalıdır.

b) Sulama suyu kanallarda gerekse parsellere verilirken ölçülmelidir. Debí ölçümünde avantajlarından dolayı Parshall savağı veya sabit yüklo orifis kullanılmalıdır. Küçuk debili kanallarda ise dik açılı ùçgen savak kullanılması önerilebilir.

c) Kanal, akarsu yataklarından geçerken otomatik sifon, tahliye yapısı gibi emniyet yapıları inşa edilerek sistemin güvenliği sağlanmalıdır. Ekonomik ve güvenli olması amacıyla sel geçitleri belirli tekerrürde gelebilecek debiye bağı olarak boyutlandırılmalıdır.

d) Sulama şebekesinde çalışabilmesi için operatöre intiyaç duyan yapılar (priz ve kapaklı çek gibi) kullanım kolaylığı bakımından tipleştirilmeli, diğer yapılar işlevine ve debiye göre teker teker boyutlandırılmalıdır. Böylece sistemin daha ekonomik olması sağlanabilir.

e) Çiftçi gruplarının organizasyon ve sorumlulukları yeniden gözden geçirilmelidir. Sistem sahiplenilmelidir.

f) Büyâk debili kanallarda kuyruk suyunun drenaj kanalına verilmesini önlemek için depo kanallari yapılimalı veya şebekenin işletiminde mansap kontrol sistemleri kullanılmalıdır.

g) Sulama projesi yapılırken şüt, dūşo ve çek yapılarına önem verilerek hidrolik hesapları tek tek yapılmalıdır.

h) Prizlerin yer seçimi daha iyi yapılarak çok daha iyi hizmet etmesi sağlanabilir.

1) Özellikle fazla miktarda sediment taşıyan akarsulardan su alınan şebekelerde çökeltim havuzları inşa edilerek işletmenin programlandığı gibi ve bakım çalışmalarının da kolay olması sağlanmalıdır.

i) Şebekedeki tâm maliyetli yapılar şebeke debisi için yeniden boyutlandirilırsa daha dāşák maliyetle sistem inşa edilebilir. En iyi çözüm bu yapılar ve sulama sistemi tasanmı için geliştirilen veya geliştirilecek bilgisayar programlarınin kullanılmasıdir.

k) Sulama projeleri hazırlanırken daha dikkatli davranilmali, uygulama projesi azerinde fazla değişiklik yapıImamalıdır. 
Çizelge 2. Sanat yapılarinın şebeke toplam maliyeti içindeki oranları (\%).

\begin{tabular}{|l|c|c|c|c|c|c|c|}
\hline $\begin{array}{c}\text { Sulama projesi } \\
\text { adı }\end{array}$ & Isaköy & Bostandere & Yenice & Gökçehüyük & Göçeri & Ulupınar & Çetme \\
\hline Akedü yapısı & 0.85 & - & - & - & - & - & - \\
\hline Priz & 2.01 & 3.10 & 7.66 & 2.07 & 6.39 & 1.04 & 1.43 \\
\hline Yol geçidi & 0.73 & 5.28 & 5.02 & 5.32 & 2.12 & 1.64 & 0.91 \\
\hline Rakortman & 1.69 & 4.85 & 3.07 & 2.55 & 2.91 & 1.49 & 1.89 \\
\hline Su dağıtım yapısı & 0.83 & 0.68 & 1.48 & 1.89 & 1.64 & 0.33 & 0.30 \\
\hline Sel geçidi & - & - & 1.93 & - & - & 0.43 & - \\
\hline Sifon & - & 6.23 & 2.03 & 4.64 & - & 4.54 & - \\
\hline Menfez & 1.02 & - & 1.37 & - & - & - & 0.77 \\
\hline Toplam & 7.13 & 20.14 & 22.56 & 16.47 & 13.06 & 9.47 & 5.30 \\
\hline
\end{tabular}

\section{Kaynaklar}

AKÜZÜM, T, ve ÖZTÜRK, F., 1988. Topraksu Yapıları. A.Ü. Ziraat Fakultesi Yayınları No:1105, Ders Kitabı No:316, Ankara.

ANONIM, 1973. Measurement of Irrigation Water. U.S. Department of Agriculture, Soil Conservation Service. National Engineering Handbook, Section 15-9, Water Resources Publications, USA.

ANONIM, 1982. Sulama Şebekelerine Ait Tip Projeler ve Abaklar. Cilt I, Sanat Yapıları, DSI Proje ve Inşaat Dairesi Başkanlığı, Ankara.

ANONIM, 1992. Issletme ve Bakım Mühendisleri Seminer Kitabı. DSI Genel Müdurlüğu, Işletme ve Bakım Dairesi Başkanlığı, Ankara.

BILEN, Ö., 1988. Sulama Kanalları Üzerindeki Yapıların Projelendirilmesi. DSl Genel Müdürluğù. Ankara.

BOS, M.G., 1989. Discharge Measurement Structures. Third Revision Edition, ILRI Publication No:20, The Netherlands.

BOSCH, B.E., SNELLEN, W.B., BROUWER, C. and HATCHO, N., 1993. Structures for Water Control and Distribution. Irrigation Water Management, Training Manual No:8, Rome.
ISRAELSEN, O.W. and HANSEN, V.E., 1967. Irrigation Principles and Practices. Third Edition, John Wiley and Sons Inc., New York.

KRAATZ, D.B. and MAHAJAN I.K., 1975. Small Hydraulic Structures. FAO Irrigation and Drainage Paper No:26, Vol. I,II, Rome.

OZZBEK, T., 1989. Hidroloji. Gazi Üniversitesi Yayın No:142, Mühendislik Mimarlık Fakültesi Yayın No:11, Ankara.

OZSOY, E., 1968. Sulama Suyu Ölçü Tesisleri (Kısa Bilgiler ile Tablolar ve Diyağramlar). DSl Genel Müdürtugŭu, Genel Yayın No:613, Grup No:X, Özel Yayın No:54, Ankara.

ÖZŞAHIN, A., 1991. Su Alma Yapıları. Köy Hizmetleri Genel Mưdürlüğü, Ankara.

ŞAHIN, L. ve GÜRELI, M.T., 1986. Sulama Suyu Ölçü Tesisleri EI Kitabı. Ankara.

UEDA, M., 1990. Design of Headworks. National Research Institute of Agricultural Engineering. Dept. Of Hydraulic Engineering, Japan. 